\title{
Immune electron microscopy and a cultural test in the diagnosis of adenovirus ocular infection
}

\author{
G. VAN RIJ, ' L. KLEPPER, ${ }^{2}$ E. PEPERKAMP,' AND G. J. P. SCHAAP ${ }^{2}$ \\ From the 'Department of Ophthalmology, Erasmus University, Eye Hospital, Schiedamse Vest 180, \\ 3011 BH Rotterdam, and the ${ }^{2}$ Laboratory of Virology, Public Health Service of Rotterdam, \\ The Netherlands
}

SUMMARY Immune electron microscopy (IEM) and virus isolation in cell culture were compared in the diagnosis of adenovirus ocular infection during an outbreak of the disease in 1979. Eleven of 14 patients with a keratoconjunctivitis clinically indicative of adenovirus infection had IEM evidence of adenovirus infection or had the virus isolated from ocular swabs. The IEM was positive in 8 patients. Virus was isolated from 10 patients. IEM was positive in one culture-negative patient. Since IEM provides a rapid and sensitive method for the detection of adenovirus in human tears, it may be a valuable diagnostic tool for the clinician.

Sporadic cases and outbreaks of acute follicular conjunctivitis caused by various types of adenovirus are well known all over the world. The most frequently used laboratory tests for the diagnosis of adenovirus ocular infection are cultural tests for virus isolation and the complement fixation test (CFT). Gibson and coworkers' ${ }^{1}$ observed no significant difference between these 2 tests when the conjunctival swabbings for the cultural test and the sera for CFT were collected at the optimum times. However, these tests are slow and require weeks for their performance. Sometimes a rapid diagnosis is desirable. Imre and coworkers $^{2}$ and Schwartz and coworkers ${ }^{3}$ used an immunofluorescent technique to demonstrate adenoviral antigens in epithelial cells on conjunctival scrapings. An experienced collector is essential for the collection of good specimens. When good specimens are collected, this is a reliable and rapid diagnostic technique. We wanted to investigate if immune electron microscopy (IEM) of human tears could be of any help for a rapid diagnosis of adenovirus ocular infection.

After we finished this study Boerner and coworkers ${ }^{4}$ reported the use of the pseudoreplica technique for the detection of adenovirus in human tears by electron microscopy. In their study 9 of 34 patients with a keratoconjunctivitis clinical indicative of adenovirus infection had EM evidence of adenovirus infection.

Correspondence to G. van Rij. Eye Hospital, Schiedamse Vest 180. 3011 BH Rotterdam. The Netherlands.

\section{Materials and methods}

Patients attending the Rotterdam Eye Clinic in 1979 with a keratoconjunctivitis suggestive of an adenovirus infection were included in this study.

Immune electron microscopy. Tears of patients were collected at the lateral canthus in a $100 \mu \mathrm{l}$ capillette (Lab. Mannheim GMBH). The capillette was held horizontal to collect the tears. Mostly about $50-100 \mu \mathrm{l}$ of tears was collected. The ends were sealed with parafilm laboratory film (American Can Company) and were sent immediately to the laboratory or refrigerated at $4^{\circ} \mathrm{C}$ before transportation. IEM was performed according to the method of Derrick, ${ }^{5}$ modified by Milne and Luisoni. ${ }^{6}$

Cultural test. A dry swab (Exogen Ltd, Glasgow) was wiped firmly, with rotation of the swab, in the lower fornix and then placed in a transport medium (buffered salt solution with gentamicin and amphotericin B) and sent immediately to the laboratory or kept at $4^{\circ} \mathrm{C}$ before transport. Each specimen was inoculated into cultures of embryonic fibroblasts and of human epitheloid cell line. The inoculated cell cultures were examinated at regular intervals for the presence of cytopathic effect. Incubation time went up to 21 days, including a blind passage for the human epithelioid cell line. When a cytopathic effect was found, a second passage of the tissue culture was done. After fixation the monolayer was transferred to a slide and stained with haematoxylin-eosin to study the characteristic intranuclear inclusions. 


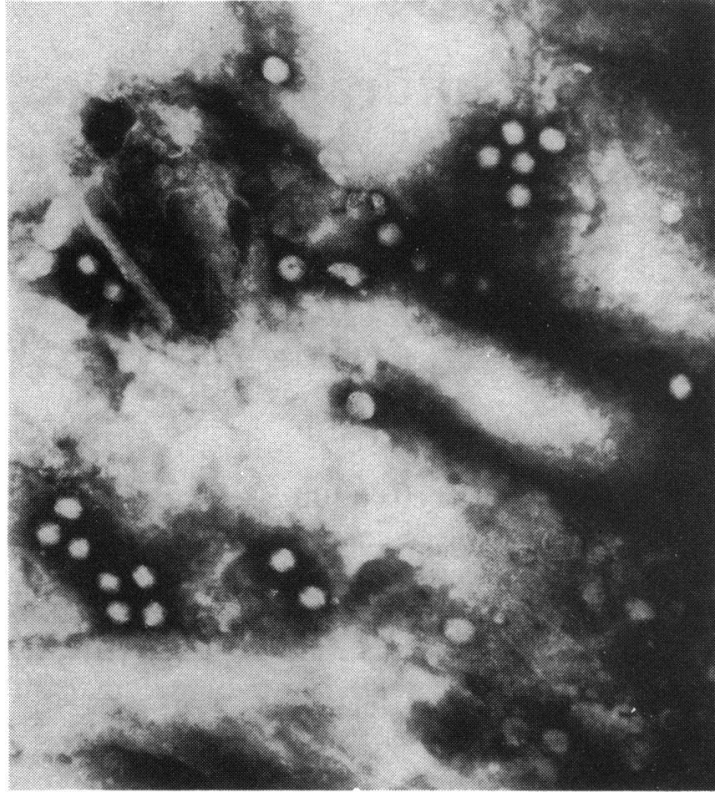

Fig. 1 Adenovirus in human tears. $(\times 45000)$.

\section{Results}

Immune electron microscopy. Fifteen tear samples of 14 patients were collected. Of these 8 were positive for adenovirus (Figs. 1 and 2). The tear samples were mostly collected during the first week of the infection. Of one patient, working in the virology department, tears were collected on the first day of symptoms. The IEM was negative. Two days later the IEM was positive for adenovirus. This is the only patient on whom we repeated the IEM after a negative result at the first examination. As we did not see any other patient on the first day of symptoms, we included this patient in the IEM-positive group.

Virus isolation. Fourteen specimens were collected of 14 patients at the same time as the tears for IEM. Adenovirus was isolated from 10 patients. The specimen of the patient working in the virology department, which was collected on the first day of symptoms, was positive for adenovirus. It yielded adenovirus $37 .{ }^{78}$ The adenovirus with which she was working before she got her infection was type 8 . The adenovirus of the other patients included in this study were not all typed, mainly because it was extremely difficult to obtain infectious virus on passaging the virus after the isolation.

\section{Discussion}

IEM and cell culture were compared in the diagnosis

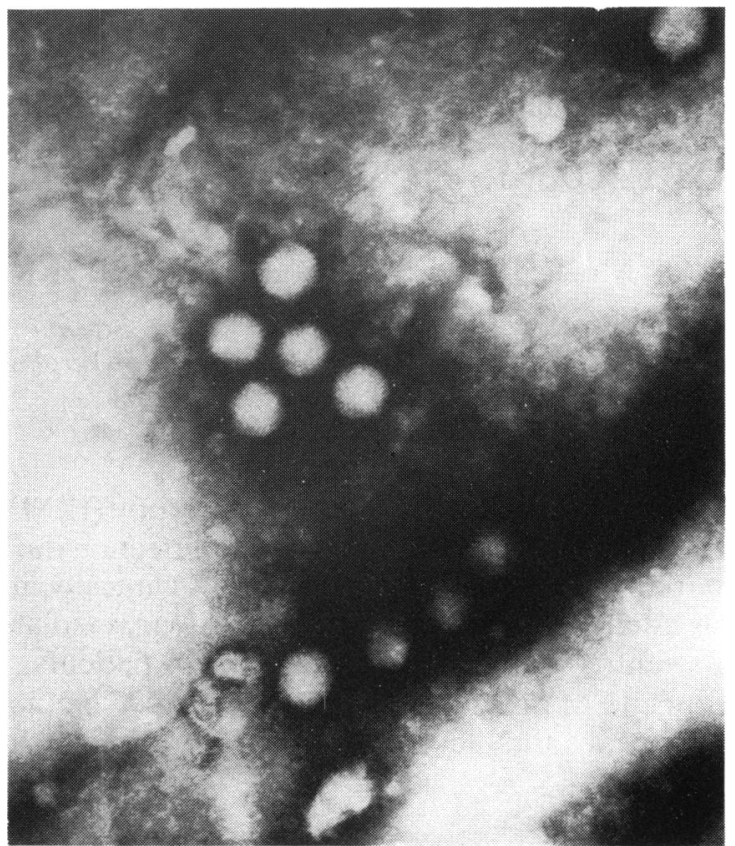

Fig. 2 Adenovirus in human tears. $(\times 95000)$.

of adenovirus ocular infection. IEM was positive in 8 of 14 patients. Virus was isolated in 10 of the 14 patients. One patient was positive for IEM and negative for adenovirus isolation. In one patient the IEM was negative on the first day of symptoms but positive 2 days later. Because the IEM is a rapid technique one can repeat the test after some days. Since IEM provides a rapid and sensitive method for the detection of adenovirus in human tears, it may be a valuable diagnostic tool for the clinician.

We are grateful to Professor Dr H. E. Henkes for his encouragement to undertake this study.

\section{References}

1 Gibson JA. Darougar S. McSwiggan DA. Thaker U. Comparative sensitivity of a cultural test and the complement fixation test in the diagnosis of adenovirus infection. BrJ Ophthalmol 1979: 63: $617-20$.

2 Imre G. Korchmáros I. Geck P. Nász I. Dán P. Antigenic specificity of inclusion bodies in epidemic keratoconjunctivitis. Ophthalmologica 1964: 148: 7-12.

3 Schwartz HS. Vastine DW, Yamashiroya H, West CE. Immunofluorescent detection of adenovirus antigen in epidemic keratoconjunctivitis. Invest Ophthalmol Visual Sci 1976; 15: 199-207.

4 Boerner CF. Lee F. Wycliffe C. Nahmias A. Cavanagh HD. Use of electron microscopy in the diagnosis of viral conjunctivitis. Proceedings of the VIth Congress of the European Society of Ophthalmologv 1980; 385-7.

5 Derrick KS. Quantitative array for plant viruses using serologically specific electron microscopy. Virology 1973; 56: 652-3. 
6 Milne RG, Luisoni E. Rapid immune electron microscopy of virus preparations. Methods Virol 1977; 6: 265-81.

8 de Jong JC. Wigand R, Wadell G, Keller D, Muxeric CJ, Schaap GJP, de Jong JC, van Bijsterveld OP. Beekhuis H. A new intermediate adenovirus type causing conjunctivitis. Arch Ophthalmol 1979; 97: 2336-8. Wermenbol AG, Schaap GJP. Adenovirus 37: Identification and characterization of a medically important new adenovirus type of subgroup D. J Med Virol 1981; 7: 105-18. 